\title{
Novel glycine-dependent inactivation of NMDA receptors in cultured hippocampal neurons
}

\author{
Yun-Feng Zhang ${ }^{1,2}$, Xia Li ${ }^{1}$, Liang-Liang Peng ${ }^{1}$, Guo-Hua Wang ${ }^{1}$, Kai-Fu Ke ${ }^{2}$, Zheng-Lin Jiang ${ }^{1}$ \\ ${ }^{1}$ Department of Neuropharmacology, Institute of Nautical Medicine, Nantong University, Nantong 226001, China \\ ${ }^{2}$ Department of Neurology, Affiliated Hospital, Nantong University, Nantong 226007, China
}

(C) Shanghai Institutes for Biological Sciences, CAS and Springer-Verlag Berlin Heidelberg 2012

\begin{abstract}
Objective Glycine acts as a co-agonist for the activation of N-methyl- $D$-aspartate receptors (NMDARs) by binding to glycine sites, thus potentiating glutamate-elicited responses and inhibiting NMDAR desensitization in a dosedependent manner. The present study aimed to characterize the glycine-dependent inactivation of NMDARs and to explore its pathophysiological significance. Methods Primary hippocampal cell cultures from embryonic days 17-18 rats were treated with NMDA or NMDA plus glycine. Patch-clamp recording and intracellular $\mathrm{Ca}^{2+}$ imaging were performed to test the effects of glycine on NMDA-activated currents and increase of intracellular free $\mathrm{Ca}^{2+}$ respectively. Immunofluorescence staining was conducted to examine NR1 internalization. Cell damage was tested with MTT method and lactate dehydrogenase leakage. Results Glycine reduced the peak current and $\mathrm{Ca}^{2+}$ influx elicited by NMDA application at concentrations $\geq 300 \mu \mathrm{mol} / \mathrm{L}$. This is a novel suppressive influence of glycine on NMDAR function, since it occurs via the NMDAR glycine-binding site, in contrast to the classic suppression, which occurs through the binding of glycine to glycine receptors. The level of membrane NMDARs was measured to evaluate whether internalization was involved. Immunohistochemical labeling showed that incubation with high concentrations of NMDA plus glycine did not change the expression of NMDARs on the cell surface when compared to the expression without glycine; hence the possibility of NMDAR internalization primed by glycine binding was excluded. Conclusion In summary, the novel suppressive effect of glycine on NMDARs was mediated via binding to the glycine site of the NMDAR and not by activation of the strychnine-sensitive glycine-receptor-gated chloride channel or by the internalization of NMDARs. The inhibitory influence of glycine on NMDARs adds a new insight to our knowledge of the complexity of synaptic transmission.
\end{abstract}

Keywords: glycine; N-methyl- $D$-aspartate receptors; calcium imaging; NMDA-NR1 subunit; hippocampal neurons; inactivation

\section{Introduction}

The N-methyl- $D$-aspartate receptor (NMDAR), one of the ionotropic glutamate receptors, plays a key role in

Correspondence author: Zheng-Lin Jiang

Tel: +86-513-85051847; Fax: +86-513-85051796

E-mail: jiangzl@ntu.edu.cn

Article ID:1673-7067(2012)05-0550-11

Received date: 2012-02-09; Accepted date: 2012-05-07 physiological and pathophysiological processes such as the development and modification of synaptic plasticity, long-term potentiation and long-term depression ${ }^{[1,2]}$, as well as in such disorders as ischemia, epilepsy, trauma, and dementia ${ }^{[1,3]}$. NMDARs are abundantly distributed throughout the central nervous system. Currently, they are considered to be unique among ligand-gated ion channels in their requirement for a necessary co-agonist, glycine, in 
addition to the synaptic neurotransmitter glutamate ${ }^{[4,5]}$. Two independent binding sites have been identified for glycine and glutamate, located on the NR1 and NR2 subunits, respectively ${ }^{[6,7]}$. It has been found that, upon binding to the glycine site, glycine potentiates the glutamate-elicited response and inhibits the desensitization of NMDARs ${ }^{[4,8,9]}$. To study the regulatory role of glycine in detail, NMDAmediated currents and $\mathrm{Ca}^{2+}$ influx were assayed in primary hippocampal neurons from juvenile rats. We were surprised to find a novel inhibitory influence of glycine on NMDARs when NMDA was administered at a high concentration. The present study was designed to characterize this glycine-dependent inactivation of NMDARs and to explore its pathophysiological significance.

\section{Materials and methods}

2.1 Animals and chemicals Sprague-Dawley rats were obtained from the Experimental Animal Center of Nantong University, Nantong, China. All procedures were in accordance with the Institutional Guidelines of Nantong University, which comply with international rules and policies, and approved by the Animal Care and Use Committee. Common inorganic salts $\left(\mathrm{NaCl}, \mathrm{KCl}, \mathrm{CaCl}_{2}, \mathrm{MgCl}_{2}\right.$ and $\mathrm{NaOH})$ were from Sinopharm Chemical Reagent Co. Ltd. (Shanghai, China); dimethylformamide, paraformaldehyde, sucrose, and glucose from Xilong Chemical Co. Ltd. (Guangzhou, China); and dimethylsulfoxide (DMSO) from Shenhe Chemical Reagent Co. Ltd. (Shanghai, China). Chemicals used for neuronal culture and the acetoxymethylester form of Fluo-3/AM were from Invitrogen Corp. (Carlsbad, CA). NMDA, glycine, MK-801, DL-2-amino-4phosphonobutytic acid ( $D L$-AP-4), dynasore, $\beta$-cytosine$D$-arabinofuranoside, cesium methanesulfonate $\left(\mathrm{CH}_{3} \mathrm{O}_{3} \mathrm{SCs}\right)$, 3-(4,5-dimethyl-2-thiazolyl)-2,5-diphenyl-2H-tetrazolium bromide (MTT), EGTA, CsOH, HEPES, Mg-ATP, NaGTP, sodium dodecylsulfate, and other chemicals (unless indicated elsewhere) were from Sigma-Aldrich Corp. (St. Louis, MO).

2.2 Cell culture and transfection Primary hippocampal cell cultures were prepared as described ${ }^{[10]}$. Dissociated hippocampal cells from embryonic days $17-18$ rats were plated onto poly- $D$-lysine-coated 96-well plates or coverslips $\left(1 \times 1 \mathrm{~cm}^{2}\right)$. Cells were grown in the plating medium with $85 \%$ high-glucose Dulbecco's minimum essential medium (DMEM, 12100-046) and 15\% fetal bovine serum (Hyclone, Logan, UT), and were incubated at $37^{\circ} \mathrm{C}$ in a humidified atmosphere of $5 \% \mathrm{CO}_{2}$. The plating medium was replaced with fresh neurobasal medium containing $98 \%$ neurobasal medium, 2\% B27 and $2 \mathrm{mmol} / \mathrm{L}$ glutamine (all from Invitrogen) every 4 days. Neurons were transfected with pcDNA3.1-GFP-NR1-1a at 7 days in vitro (DIV) using a Lipofectamine 2000 transfection kit (Invitrogen) to test NR1 internalization.

\subsection{Patch-clamp recording of NMDA-activated cur-}

rents Current responses $\left(I_{\mathrm{NMDA}}\right)$ were elicited in cultured hippocampal neurons (12-14 DIV) perfused with NMDA. Patch pipettes had resistances of 5-8 $\mathrm{M} \Omega$ when filled with the following solution (in mmol/L): $\mathrm{CH}_{3} \mathrm{O}_{3} \mathrm{SCs} 135, \mathrm{NaCl}$ 8, HEPES 10, EGTA 0.5, Mg-ATP 4, and Na-GTP 0.3 (pH 7.2 , adjusted with $1 \mathrm{~mol} / \mathrm{L} \mathrm{CsOH}$, and osmolarity 300-310 mOsm adjusted with sucrose). Recordings of $I_{\mathrm{NMDA}}$ were performed in the following bath solution (in $\mathrm{mmol} / \mathrm{L}$ ): $\mathrm{NaCl} 150, \mathrm{KCl} 3$, HEPES $10, \mathrm{CaCl}_{2} \cdot 2 \mathrm{H}_{2} \mathrm{O} 3$, and glucose $8 \mathrm{pH} 7.4$, adjusted with $1 \mathrm{~mol} / \mathrm{L} \mathrm{NaOH}$, and osmolarity 300-310 mOsm adjusted with sucrose), using a MultiClamp 700A amplifier, Digidata 1320A AD converter and pCLAMP 8.0 software (Axon Instruments, Forster City, $\mathrm{CA})$. The junction potential between micropipette and bath solution was $-9.9 \mathrm{mV}$, as calculated using Clampex 8.0 (in pCLAMP 8.0) and nulled just before forming a gigaseal. In most experiments, the series resistance (Rs) before compensation was $10-20 \mathrm{M} \Omega$. Routinely, $70 \%-80 \%$ of the Rs was compensated. Only neurons with an Rs $<20 \mathrm{M} \Omega$ were selected for further tests. All NMDA currents were recorded while the membrane potential was held at $-70 \mathrm{mV}$, except as otherwise noted.

The application of NMDA onto cultured neurons was performed via a perfusion system (MPS-2; World Precision Instruments, Sarasota, FL). The tip (diameter $250 \mu \mathrm{m}$ ) of the drug application pipette was usually placed $100 \mu \mathrm{m}$ away from the recorded cell. To avoid drug accumulation in the bath, each 2-s pulse of drug application was fol- 
lowed by 2 min of rinsing. The ambient temperature was held between 23 and $25^{\circ} \mathrm{C}$.

The degree of desensitization of NMDA currents was determined according to the following equation: desensitization score $=1-I_{\mathrm{ss}} / I_{\mathrm{p}}$, where $I_{\mathrm{p}}$ is the peak current, and $I_{\mathrm{ss}}$ is the steady-state current of $I_{\mathrm{NMDA}}$ (Fig. 1). The degree of desensitization was positively related to the calculated desensitization score.

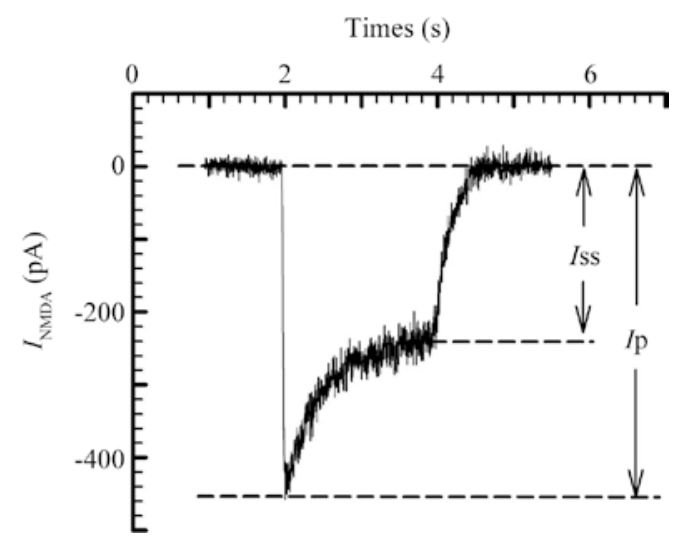

Fig. 1. NMDA-activated current $\left(I_{\mathrm{NMDA}}\right)$ recorded using whole-cell mode in a cultured hippocampal neuron. $I_{\mathrm{p}}$, peak current; $I_{\mathrm{ss}}$, steadystate current of $I_{\mathrm{NMDA}}$.

2.4 Intracellular $\mathrm{Ca}^{2+}$ imaging Fluo-3/AM, a fluorescent $\mathrm{Ca}^{2+}$ indicator, was dissolved in DMSO with the final working concentration of DMSO at $0.1 \%$. At $12-14$ DIV, the cultured hippocampal neurons were loaded with 5 $\mu \mathrm{mol} / \mathrm{L}$ Fluo-3/AM for $45 \mathrm{~min}$ at $37^{\circ} \mathrm{C}$ in the bath solution. After washing three times in fresh bath solution, the neurons were incubated at $37^{\circ} \mathrm{C}$ for another $30 \mathrm{~min}$ to complete the de-esterification of Fluo-3/AM. The fluorescence intensity (excitation at $485 \mathrm{~nm}$, emission at $525 \mathrm{~nm}$ ) was recorded every $10 \mathrm{~s}$ for $5 \mathrm{~min}$ using a laser scanning confocal microscope (TCS SP2, Leica Microsystems, Heidelberg, Germany). All image data were collected and analyzed with Leica software. The increase of intracellular free $\mathrm{Ca}^{2+}\left(\left[\mathrm{Ca}^{2+}\right]_{\mathrm{i}}\right)$ was determined according to the following equation: $\left[\mathrm{Ca}^{2+}\right]_{\mathrm{i}}$ increase $(\%)=\left(\mathrm{F}_{525}-\mathrm{F}_{\text {base, } 525}\right) / \mathrm{F}_{\text {base, } 525} \times$ $100 \%$, where $\mathrm{F}_{525}$ is the fluorescence intensity measured after each treatment, and $\mathrm{F}_{\text {base, } 525}$ is the basal fluorescence intensity.

\subsection{Immunofluorescence procedures and internaliza-} tion assays Hippocampal neurons at 14 DIV were used for the internalization assays. Neurons were pretreated with DMSO or $80 \mathrm{nmol} / \mathrm{L}$ dynasore for $10 \mathrm{~min}$, then NMDA or NMDA plus glycine were added to the medium at $37^{\circ} \mathrm{C}$ for 3 min. For live staining, the above neurons, which had been transfected with pcDNA3.1-GFP-NR1-1a at 7 DIV (against the extracellular region), were labeled with rabbit anti-GFP antibody (1:200; Chemicon) in cold Hank's balanced salt solution (HBSS; Gibco, Carlsbad, CA) for $30 \mathrm{~min}$ to visualize the surface receptors. All procedures were conducted at $4{ }^{\circ} \mathrm{C}$ to prevent receptor-antibody internalization. The cells were then extensively washed with cold HBSS prior to incubation with Cy3 goat anti-rabbit IgG $(\mathrm{H}+\mathrm{L})(1: 1000$; Invitrogen) in HBSS for $10 \mathrm{~min}$. Subsequently, the cells were washed with HBSS at $4^{\circ} \mathrm{C}$. For endogenous receptor staining, the neurons were fixed with $4 \%$ paraformaldehyde in phosphate-buffered saline for $10 \mathrm{~min}$ at room temperature (RT), then permeabilized in ice-cold methanol for $8 \mathrm{~min}$ at $-20^{\circ} \mathrm{C}$ to measure the total receptors, washed in wash buffer (WB, $10 \mathrm{mmol} / \mathrm{L}$ phosphate buffer, $\mathrm{pH}$ 7.4) three times for $5 \mathrm{~min}$ at RT and incubated with rabbit anti-GFP antibody (1:200; Chemicon) in staining buffer (SB, $100 \mathrm{mmol} / \mathrm{L}$ phosphate buffer, $\mathrm{pH} 7.4$, containing $0.5 \%$ Triton $\mathrm{X}-100$ and $1 \%$ bovine serum albumin) overnight at $4{ }^{\circ} \mathrm{C}$. The cells were then washed three times in WB for 10 min at RT. Following incubation with secondary antibody (Alexa Fluor 488 goat anti-rabbit $\operatorname{IgG}(\mathrm{H}+\mathrm{L})$, 1:1 000, Invitrogen) in SB for $1 \mathrm{~h}$ at room temperature, the cells were washed three times in WB for $10 \mathrm{~min}$ at RT. Immunofluorescence images were then collected and processed with a laser scanning confocal microscope (TCS SP2, Leica Microsystems). NR1 internalization assays and quantitation were performed according to the ratio of surface/total receptor expression.

2.6 Measurement of cell damage Cell damage was assessed by measuring neuronal viability with the MTT method, as well as lactate dehydrogenase (LDH) leakage. After $1 \mathrm{~h}$ of NMDA exposure, the culture medium was removed from the 96-well plate, and the neurons (12-14 DIV) were rinsed twice with bath solution. Then $25 \mu \mathrm{L}$ 
MTT was added to each well to a final concentration of $0.1 \%$. Following incubation at $37^{\circ} \mathrm{C}$ for $4 \mathrm{~h}, 100 \mu \mathrm{L} 20 \%$ sodium dodecylsulfate (dissolved in dimethylformamide) was mixed into each well and left for $20 \mathrm{~h}$ to dissolve the resultant dark blue crystals. The absorbance of each well at $570 \mathrm{~nm}\left(\mathrm{OD}_{570}\right)$ was measured with a Universal Microplate Reader (ELx800, BioTek Instruments, Inc., Winooski, VT).

LDH activity was measured with a kit (Jiancheng Bioengineering Institute, Nanjing, China) according to the manufacturer's instructions. Briefly, after $1 \mathrm{~h}$ of NMDA exposure, $0.4 \mathrm{~mL}$ culture medium was mixed with $1.3 \mathrm{~mL}$ nicotinamide adenine dinucleotide (NADH) and $1.3 \mathrm{~mL}$ sodium pyruvate. Both agents were dissolved in potassium phosphate buffer $\left(100 \mathrm{mmol} / \mathrm{L} \mathrm{K}_{2} \mathrm{HPO}_{4}, \mathrm{pH}\right.$ adjusted to 7.5 with $\mathrm{KH}_{2} \mathrm{PO}_{4}$ ). The mixed solution was immediately assayed with a spectrophotometer (UV-2450, Shimadzu Corp., Kyoto, Japan) by monitoring the conversion of $\mathrm{NADH}$ to NAD at $340 \mathrm{~nm}$ at $37^{\circ} \mathrm{C}$, coupled with the reduction of pyruvate to lactate. $\mathrm{LDH}$ activity is expressed as units/mL, with one unit representing the amount of $\mathrm{LDH}$ that causes a decrease of 0.001 absorbance units of NADH per minute in the presence of sodium pyruvate. The same experiments were repeated once again to measure $\mathrm{LDH}$ and neuronal viability.

2.7 Statistical analysis Clampfit 8.0 (Axon Instruments, Forster City, CA), ImageJ (National Institutes of Health, USA) and SigmaPlot 2001 (Jandel Scientific, Costa Madre, CA) were used for data analysis and plotting. All data are presented as mean $\pm \mathrm{SD}$. Data from multiple groups were analyzed with one-way ANOVA and post hoc NewmanKeuls test. $P<0.05$ was considered statistically significant.

\section{Results}

3.1 Inhibitory influence of glycine on NMDA-elicited current Whole-cell recordings were performed on cultured hippocampal neurons at 12-14 DIV. When neurons were clamped near the resting potential in $\mathrm{Mg}^{2+}$-free extracellular solution, $30 \mu \mathrm{mol} / \mathrm{L}$ NMDA-evoked inward peak currents showed dose-dependent glycine activation in all neurons tested (Fig. 2A). Meanwhile, the desensitization score of $I_{\mathrm{NMDA}}$ decreased with increasing glycine concen- tration (Fig. 2C). However, when the NMDA concentration was raised to $300 \mu \mathrm{mol} / \mathrm{L}$, we stumbled across the inhibition of the peak current by glycine (Fig. 2B), while the desensitization score still decreased with increasing glycine concentration (Fig. 2D). This is inconsistent with the previous view that glycine acts as a co-agonist for NMDAR activation by binding to the glycine site, potentiates the glutamate-elicited response, and decreases the NMDAR desensitization in a dose-dependent manner. Besides, we used $D L-\mathrm{AP}-4$, a non-competitive NMDAR antagonist as a positive control to test the inhibitory effect on both 30 $\mu \mathrm{mol} / \mathrm{L}$ and $300 \mu \mathrm{mol} / \mathrm{L}$ NMDA-evoked currents. Results showed that pre-incubation with $D L-\mathrm{AP}-4$ for $10 \mathrm{~min}$ inhibited the NMDA current significantly while pretreatment for $20 \mathrm{~min}$ suppressed the inward current. Examples of the effect of glycine on the peak current and the desensitization of $I_{\mathrm{NMDA}}$ with the application of NMDA at 30 and 300 $\mu \mathrm{mol} / \mathrm{L}$ are shown in Fig. $2 \mathrm{E}$ and F, respectively.

3.2 Inhibitory influence of glycine on NMDA-elicited $\mathrm{Ca}^{2+}$ influx To verify the above results, we performed free- $\mathrm{Ca}^{2+}$ imaging by confocal microscopy in living neurons. Similar to the results of $I_{\mathrm{NMDA}}$ recording, glycine increased $\mathrm{Ca}^{2+}$ influx as a function of concentration in the presence of $30 \mu \mathrm{mol} / \mathrm{L}$ NMDA (Fig. 3A, C), but decreased $\mathrm{Ca}^{2+}$ influx when $300 \mu \mathrm{mol} / \mathrm{L}$ NMDA was applied (Fig. 3B, D). We also found that the peak $\left[\mathrm{Ca}^{2+}\right]_{\mathrm{i}}$ induced by NMDA increased in a dose-dependent manner without the addition of glycine (Fig. 3E, F). However, it changed in a different way in the presence of glycine, i.e., when the concentration of NMDA was continuously augmented in the presence of glycine at $0.3 \mu \mathrm{mol} / \mathrm{L}$, glycine elevated the amplitude of the $\left[\mathrm{Ca}^{2+}\right]_{\mathrm{i}}$ increase evoked by NMDA at 10 and $30 \mu \mathrm{mol} / \mathrm{L}$, but not at $100 \mu \mathrm{mol} / \mathrm{L}$, and it significantly reduced the amplitude of the $\left[\mathrm{Ca}^{2+}\right]_{\mathrm{i}}$ elevation elicited by NMDA at 300 $\mu \mathrm{mol} / \mathrm{L}$ and $1 \mathrm{mmol} / \mathrm{L}$ (Fig. 3E, F).

\subsection{NMDAR internalization does not occur on the cell} membrane, regardless of being primed by glycine binding It is possible that the observed inhibitory effect was due to decreased numbers of cell-surface NMDARs; in other words, high concentrations of NMDA plus glycine may contribute to the priming of receptor internalization, which 

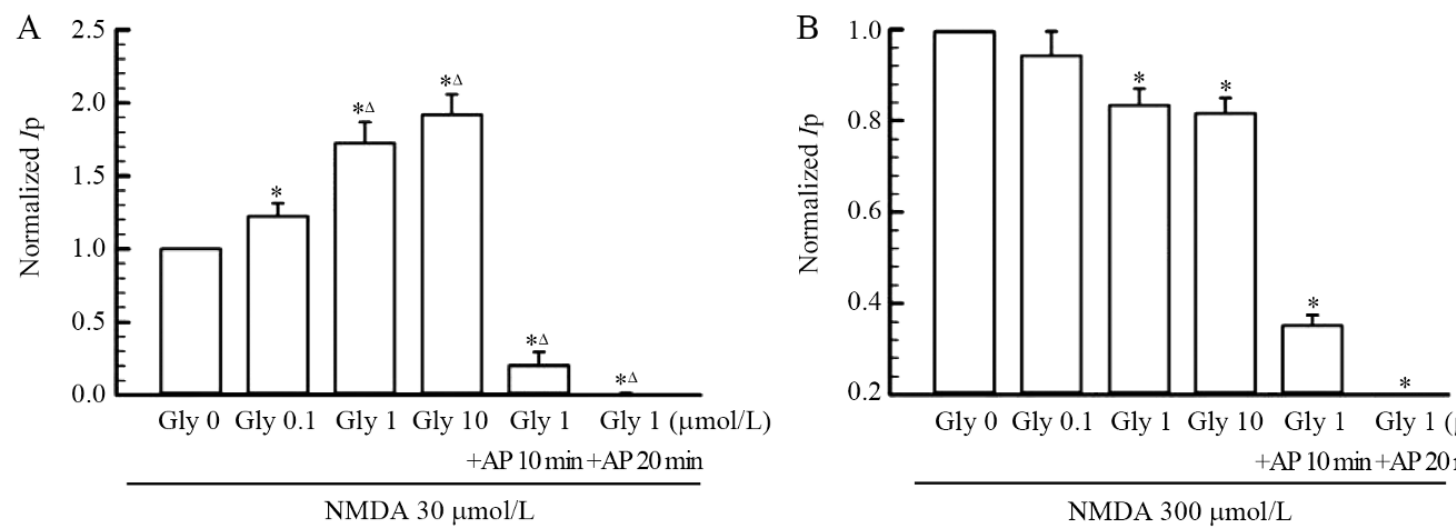

Gly 0 Gly 0.1 Gly 1 Gly 10 Gly 1 Gly $1(\mu \mathrm{mol} / \mathrm{L})$

$$
+\mathrm{AP} 10 \mathrm{~min}+\mathrm{AP} 20 \mathrm{~min}
$$

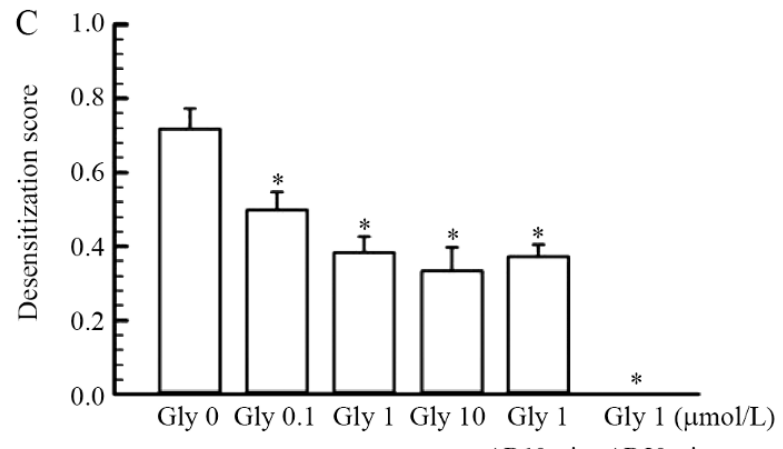

$+\mathrm{AP} 10 \mathrm{~min}+\mathrm{AP} 20 \mathrm{~min}$
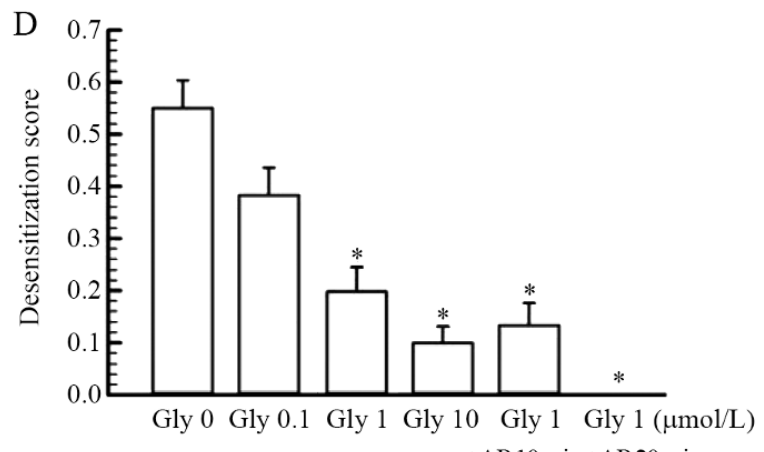

NMDA $30 \mu \mathrm{mol} / \mathrm{L}$

\section{$+\mathrm{AP} 10 \mathrm{~min}+\mathrm{AP} 20 \mathrm{~min}$}

NMDA $300 \mu \mathrm{mol} / \mathrm{L}$
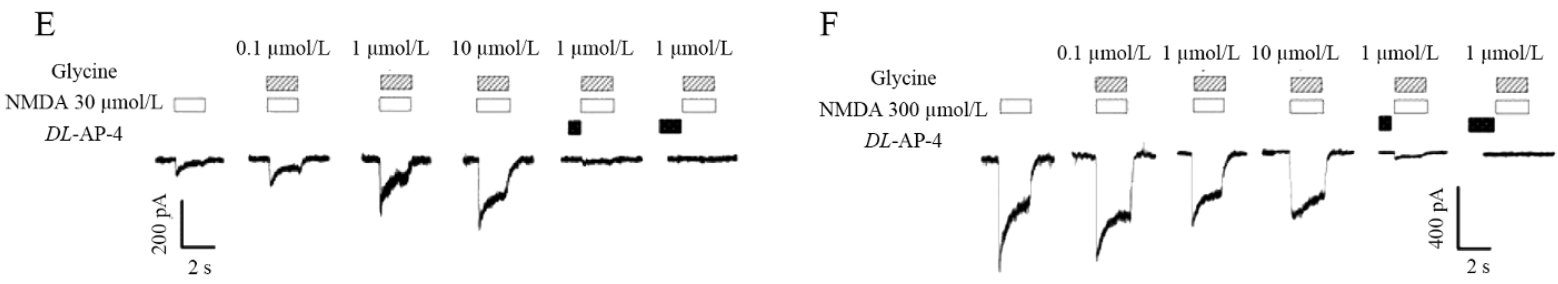

Fig. 2. Effects of glycine (Gly) on NMDA-activated peak current and desensitization. A: Effects of glycine on the peak $I_{\mathrm{NMDA}}$ elicited by $30 \mu \mathrm{mol} / \mathrm{L}$ NMDA $(n=9)$ with or without pretreatment with $1 \mathrm{mmol} / \mathrm{L} D L-\mathrm{AP}-4$ (AP) for $10 \mathrm{~min}$ and $20 \mathrm{~min}(n=3)$. B: Effects of glycine on the peak $I_{\mathrm{NMDA}}$ elicited by $300 \mu \mathrm{mol} / \mathrm{L}$ NMDA $(n=7)$ with or without pretreatment with $1 \mathrm{mmol} / \mathrm{L} D L-A P-4$ for $10 \mathrm{~min}$ and $20 \mathrm{~min}(n=3)$. C: Influence of glycine on the desensitization score of $I_{\mathrm{NMDA}}$ elicited by $30 \mu \mathrm{mol} / \mathrm{L} \mathrm{NMDA}(n=9)$ and inhibition by the antagonist, $1 \mathrm{mmol} / \mathrm{L}$ $D L-A P-4(n=3)$, as control. D: Influence of glycine on the desensitization score of $I_{\mathrm{NMDA}}$ elicited by $300 \mu \mathrm{mol} / \mathrm{L}$ NMDA $(n=7)$ and inhibition by the antagonist, $1 \mathrm{mmol} / \mathrm{L} D L-A P-4(n=3)$, as control. E: Examples of the effect of glycine on $30 \mu \mathrm{mol} / \mathrm{L}$ NMDA-evoked currents with or without $D L$-AP-4. F: Examples of the effect of glycine on $300 \mu \mathrm{mol} / \mathrm{L}$ NMDA-evoked currents with or without $D L$-AP-4. *P<0.05 vs NMDA without glycine; ${ }^{A} P<0.05$ vs with $0.1 \mu \mathrm{mol} / \mathrm{L}$ glycine.

would lead to a decrease in NMDAR currents. Thus, we sought to determine whether or not the expression of NMDAR on the neuronal surface was reduced by 300 $\mu \mathrm{mol} / \mathrm{L}$ NMDA plus glycine. For this, we used NR1-GFP extracellular domain recombinant protein and live staining at $4^{\circ} \mathrm{C}$, both of which block the further endocytosis of membrane receptors. However, there was no significant differ- ence in receptor expression after the application of 300 $\mu \mathrm{mol} / \mathrm{L}$ of NMDA, with or without glycine. In contrast, when we pretreated the cultured hippocampal neurons with $80 \mu \mathrm{mol} / \mathrm{L}$ dynasore, a cell-permeable dynamin inhibitor that prevents endocytosis, we found that the expression of membrane receptors increased significantly in comparison with non-pretreated neurons (Fig. 4A, B). 
A

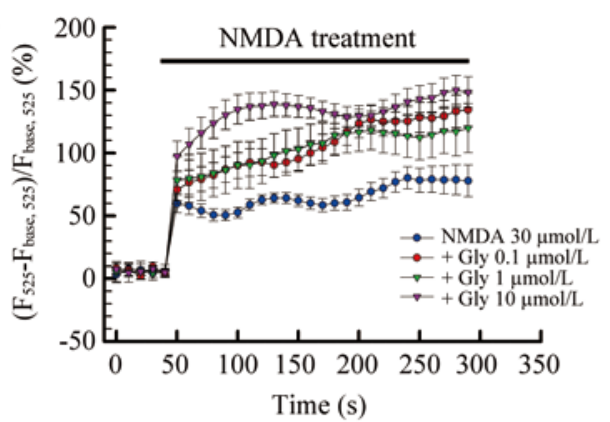

$\mathrm{C}$

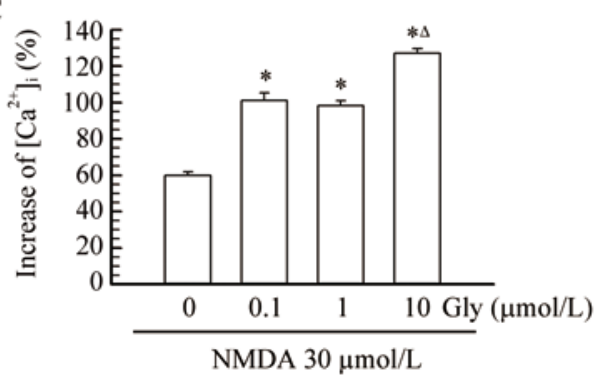

B

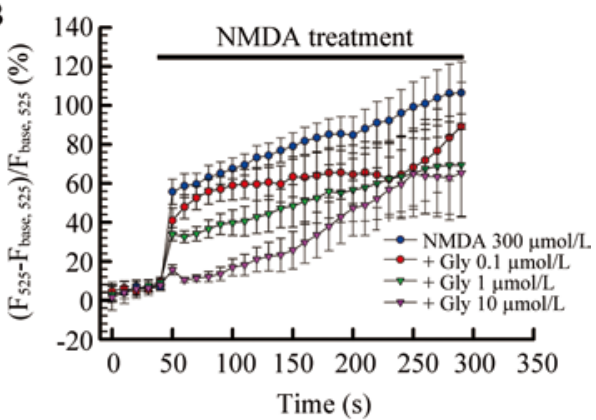

$\mathrm{D}$

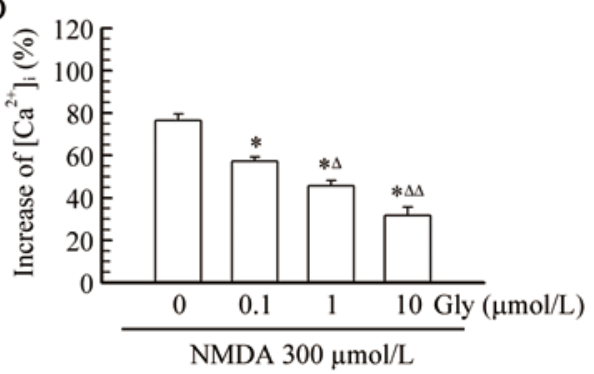

$\mathrm{E}$
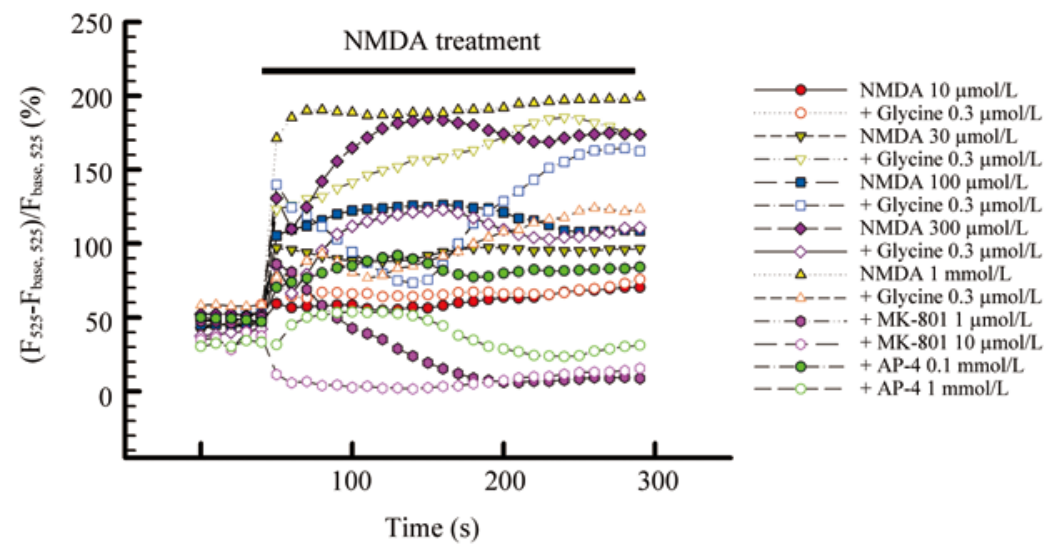

F

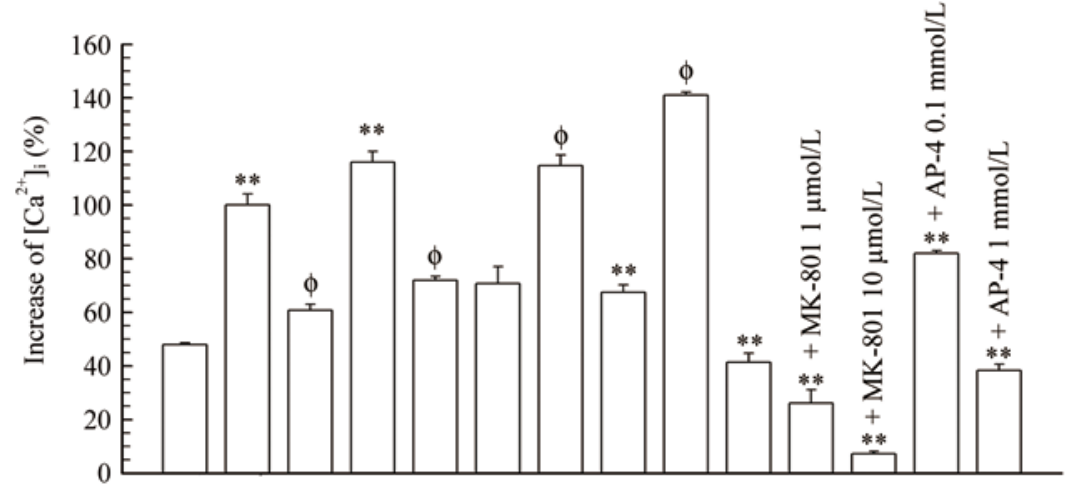

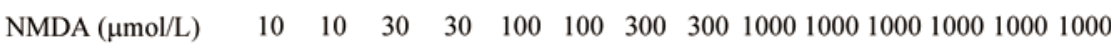
Gly $0.3 \mu \mathrm{mol} / \mathrm{L}$

Fig. 3. Effects of glycine (Gly) on NMDA-elicited $\mathrm{Ca}^{2+}$ influx. A and C: Dose-dependent facilitating effect of glycine on $\mathrm{Ca}^{2+}$ influx elicited by $30 \mu \mathrm{mol} / \mathrm{L}$ NMDA $(n=20)$. B and D: Dose-dependent inhibitory effect of glycine on $\mathrm{Ca}^{2+}$ influx elicited by $300 \mu \mathrm{mol} / \mathrm{L}$ NMDA $(n=20)$. E and F: Effect of glycine on the dose-response of NMDA-elicited $\mathrm{Ca}^{2+}$ influx $(n=20)$. The effects of MK-801 and $D L-\mathrm{AP}-4$ served as controls. ${ }^{*} P<0.05,{ }^{* * P}<0.01$ s NMDA without glycine; ${ }^{\Delta} P<0.05,{ }^{\Delta A} P<0.01$ vs with $0.1 \mu \mathrm{mol} / \mathrm{L}$ glycine; ${ }^{\phi} P<0.01$ vs $10 \mu \mathrm{mol} / \mathrm{L}$ NMDA alone. 
A
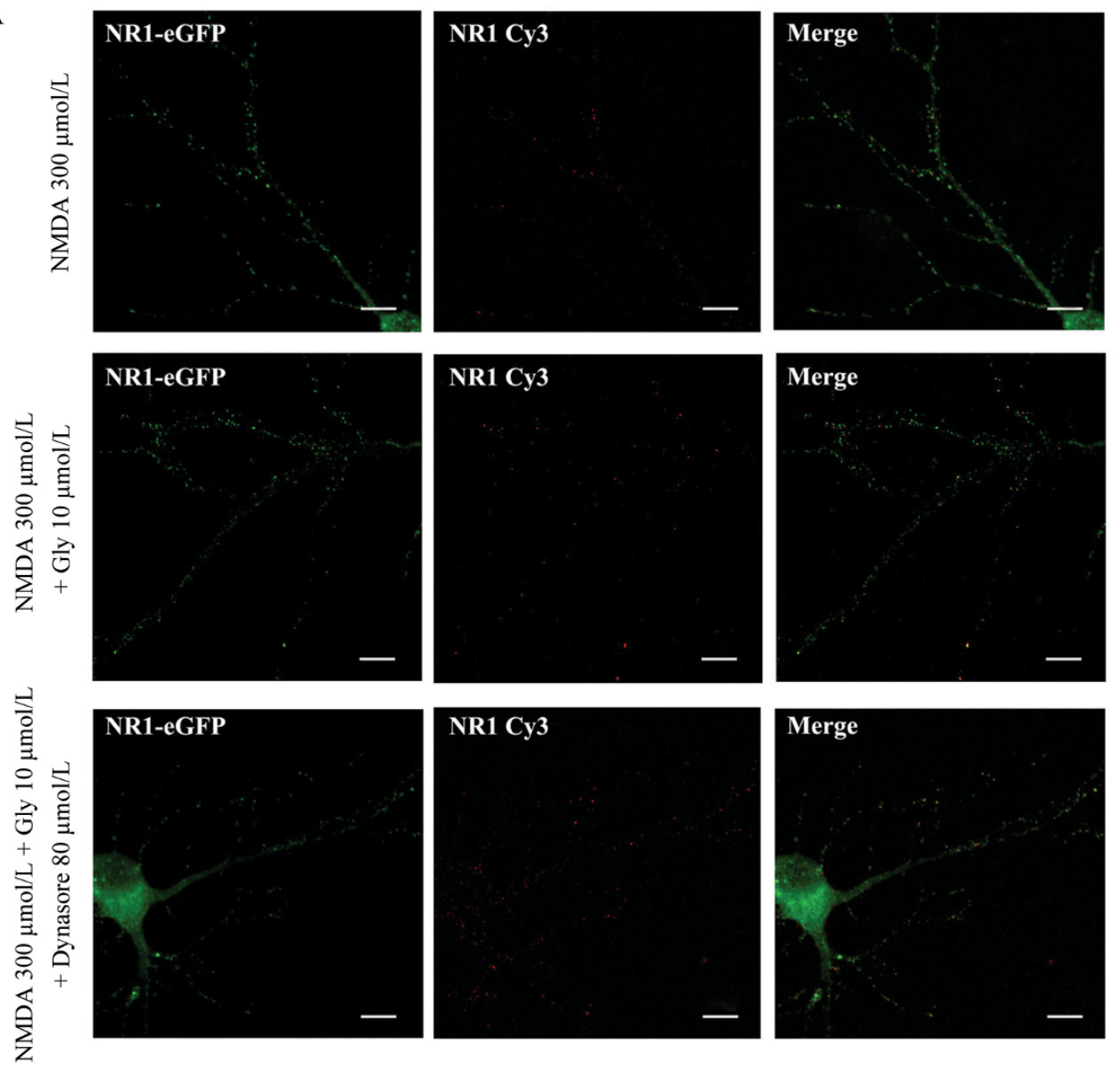

B

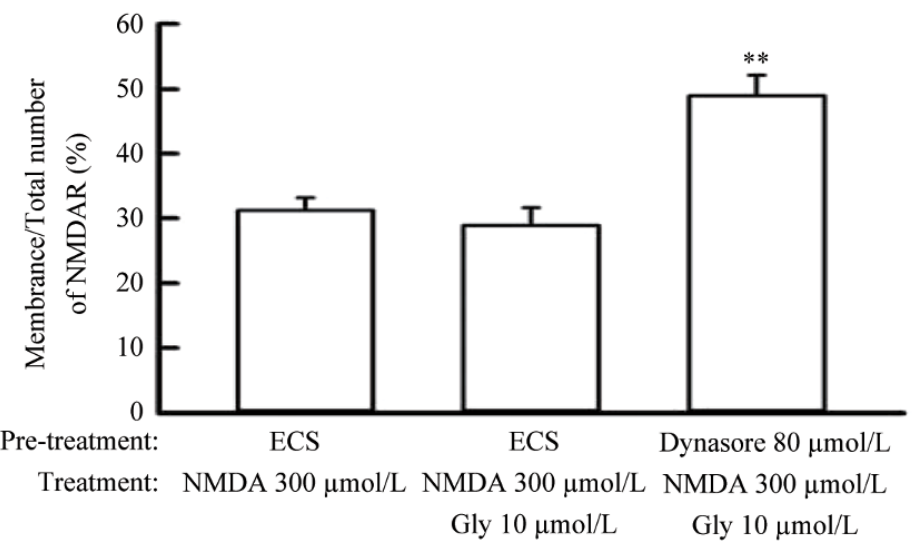

Fig. 4. Immunofluorescence images of NR1 expression in the hippocampal neuron. A: Immunofluorescence to NR1-GFP-Alex 488 (left column, green) and NR1-GFP-Cy3 (middle column, red) was performed in permeabilized (total NR1; left columns) and non-permeabilized (membrane NR1; middle columns) cells to analyze the patterns of NR1 expression of surface/total colocalization. Areas of overlapping (yellow, right columns) indicate the puncta of NR1 expression on the cell surface of membrane. Upper panels: $300 \mu \mathrm{mol} / \mathrm{L} \mathrm{NMDA}$; middle and lower panels: $300 \mu \mathrm{mol} / \mathrm{L}$ NMDA plus $10 \mu \mathrm{mol} / \mathrm{L}$ glycine (Gly) with (lower) and without (middle) 10-min pretreatment with $80 \mu \mathrm{mol} / \mathrm{L}$ dynasore at $37^{\circ} \mathrm{C}$. Scale bars, $20 \mu \mathrm{m}$. B: Histogram showing the ratio of surface/total NMDARs (mean \pm SEM) quantified by live staining of hippocampal neurons in primary culture. Cultures $(n=25,29$, and 18 in three separate experiments) were exposed to $300 \mu \mathrm{mol} / \mathrm{L}$ NMDA alone or with $10 \mu \mathrm{mol} / \mathrm{L}$ glycine with or without pretreatment with $80 \mu \mathrm{mol} / \mathrm{L}$ dynasore. ${ }^{* * P}<0.01$ vs NMDA plus glycine without dynasore. ESC, extracellular solution. 
3.4 Role of the glycine-binding site in the inhibitory influence of glycine on NMDA responses To identify the potential target of the inhibitory effect of glycine on NMDARs, we tested whether the phenomenon still occurred after pretreatment with 7-CK (an antagonist at the NMDAR glycine site) or strychnine (an antagonist of glycine receptors). We found that 7-CK blocked the glycinemediated inhibition of the $\left[\mathrm{Ca}^{2+}\right]_{\mathrm{i}}$ increase induced by 1 $\mathrm{mmol} / \mathrm{L}$ NMDA, while 7-CK itself did not have any effect on $\mathrm{Ca}^{2+}$ influx. On the contrary, strychnine at $10 \mathrm{nmol} / \mathrm{L}$ did not have any influence on the inhibitory effect of glycine on the increase of $\left[\mathrm{Ca}^{2+}\right]_{\mathrm{i}}$ evoked by $1 \mathrm{mmol} / \mathrm{L}$ NMDA (Fig. 5A, B).

3.5 Influence of glycine on viability of neurons exposed to NMDA To investigate the potential pathophysiological significance of the inhibitory influence of glycine on NMDARs at higher concentrations of NMDA, we measured the viability of neurons and LDH leakage from

A

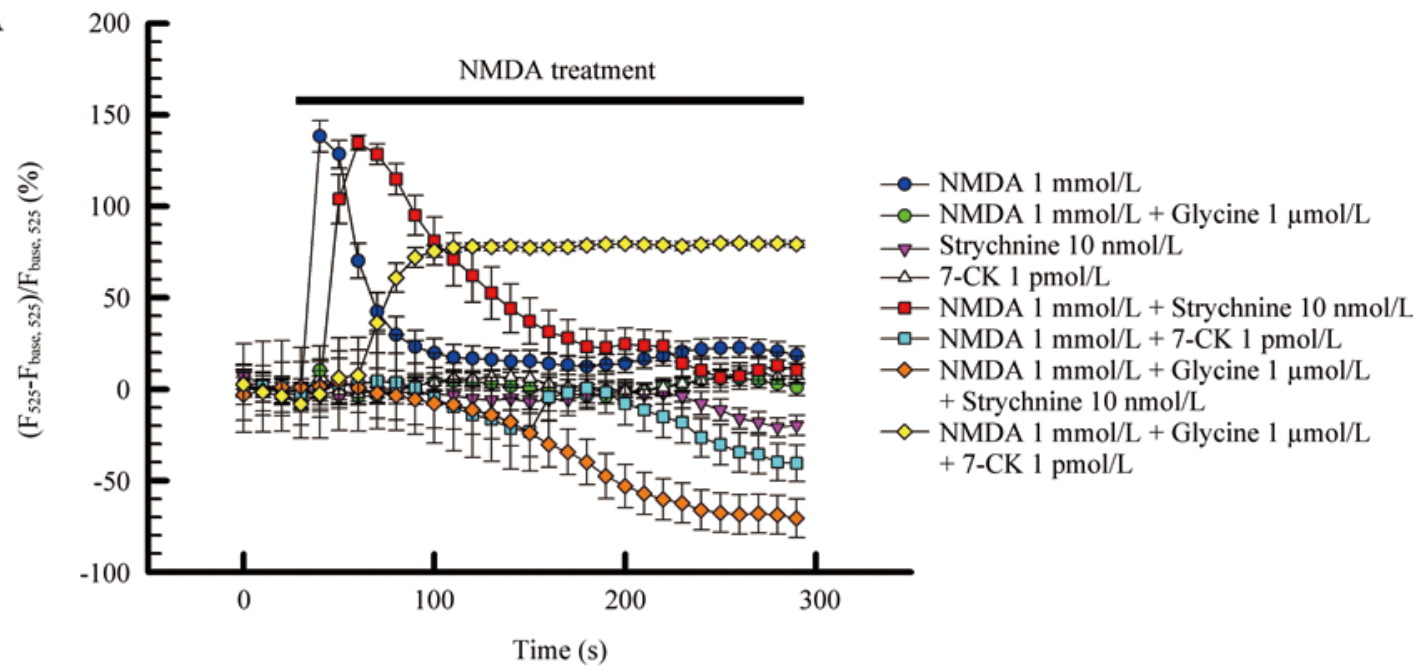

B

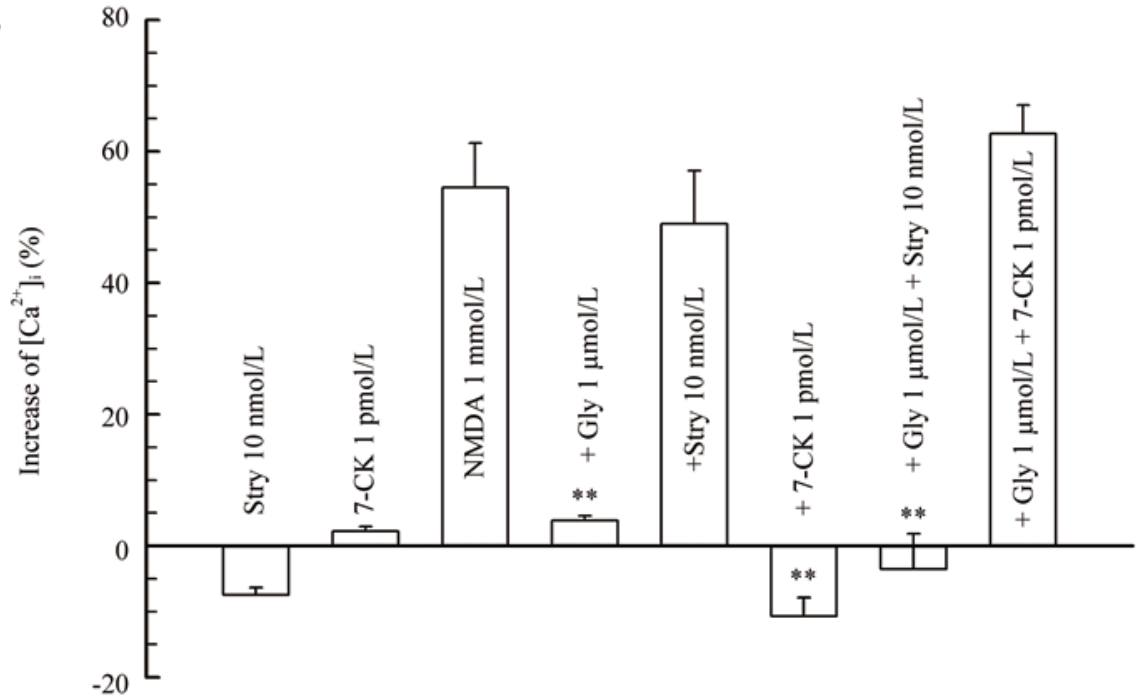

Fig. 5. A: Blockade by the glycine-binding site antagonist 7-CK of the inhibitory effect of glycine on $\mathrm{Ca}^{2+}$ influx elicited by high concentration of NMDA $(n=$ 16). B: Histograms show the effects of the glycine (Gly) site inhibitor $7-\mathrm{CK}$ and the glycine receptor antagonist strychnine (Stry) on $\mathrm{Ca}^{2+}$ influx. $* * P$ 0.01 vs NMDA without glycine. 

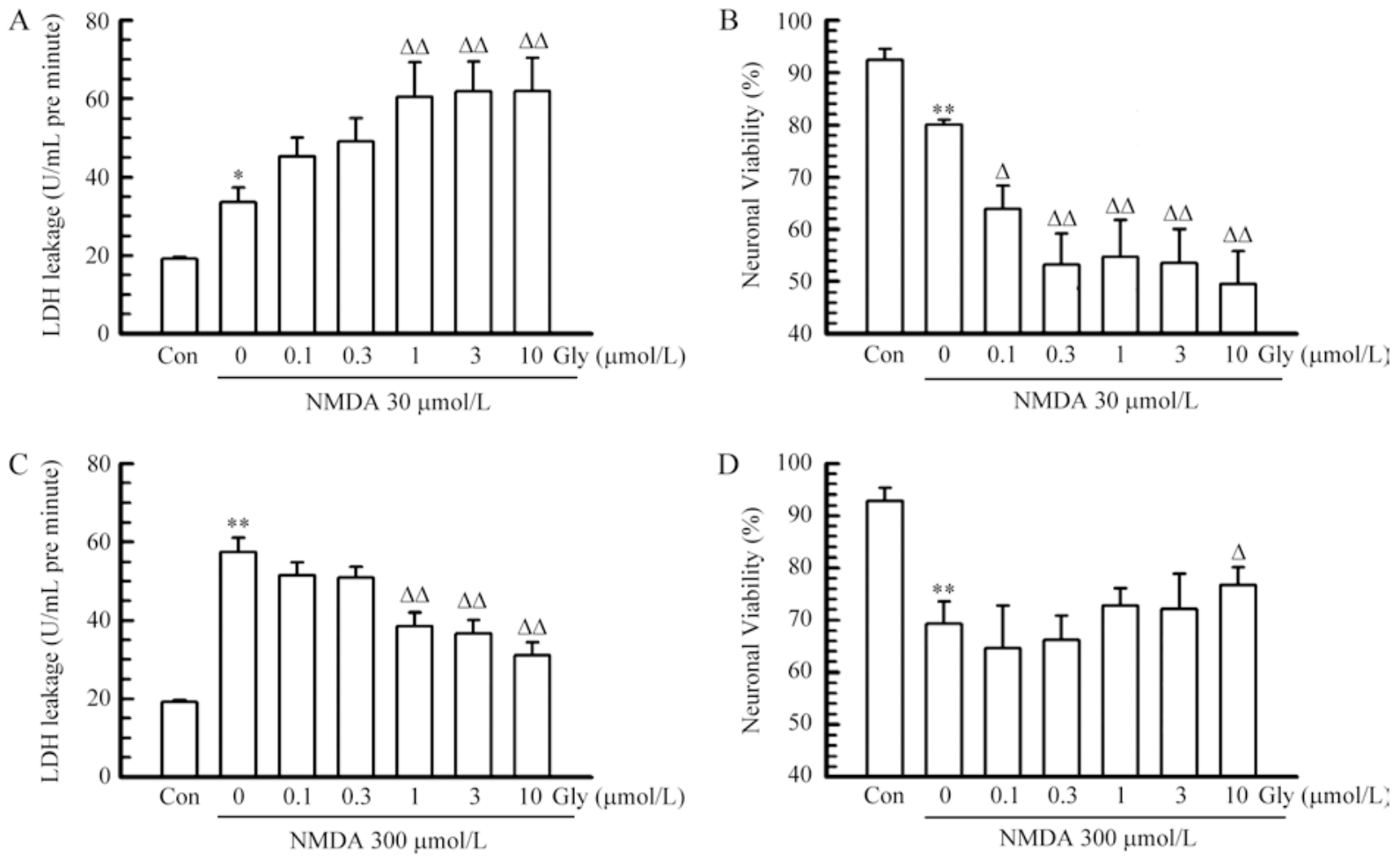

Fig. 6. Influence of glycine (Gly) on the cell-damaging effects of different concentrations of NMDA. A: LDH leakage from cultured hippocampal neurons with 1-h exposure to $30 \mu \mathrm{mol} / \mathrm{L}$ NMDA and different concentrations of glycine $(n=8)$. B: Cell viability after exposure to $30 \mu \mathrm{mol} / \mathrm{L}$ NMDA and different concentrations of glycine $(n=10)$. C: LDH leakage from hippocampal neurons exposed to $300 \mu \mathrm{mol} / \mathrm{L} \mathrm{NMDA}$ and different concentrations of glycine $(n=8)$. D: Neuronal viability after exposure to $300 \mu \mathrm{mol} / \mathrm{L}$ NMDA and different concentrations of glycine $(n=10) .{ }^{*} P<0.05, * * P<0.01 v s$ control (Con); ${ }^{\Delta} P<0.05,{ }^{\Delta \Lambda} P<0.01$ vs NMDA alone.

hippocampal neurons exposed to combinations of different concentrations of NMDA and glycine. We found that glycine dose-dependently increased the LDH leakage (Fig. 6A) and reduced the viability (Fig. 6B) when NMDA was applied at $30 \mu \mathrm{mol} / \mathrm{L}$. Therefore, we postulate that glycine can facilitate NMDA-induced neurotoxicity. In contrast, when NMDA was used at $300 \mu \mathrm{mol} / \mathrm{L}$, glycine reversed the NMDA-induced LDH leakage dose-dependently, and the viability was significantly elevated by glycine at $10 \mu \mathrm{mol} / \mathrm{L}$ (Fig. $6 \mathrm{D}, P<0.05$ ). These results indicate that glycine can protect hippocampal neurons against the excitotoxicity induced by higher concentrations of NMDA.

\section{Discussion}

Glycine is well known as a co-agonist in the activation of NMDARs. However, in the present study, we discovered that glycine not only played a co-agonist role but also exerted an inhibitory influence on NMDARs if the concentration of NMDA was raised to $300 \mu \mathrm{mol} / \mathrm{L}$ in cultured rat hippocampal neurons. Glycine dose-dependently inhibited the peak current and $\mathrm{Ca}^{2+}$ influx elicited by 300 $\mu \mathrm{mol} / \mathrm{L}$ NMDA. To our knowledge, this inhibitory effect of glycine on NMDARs has not been reported previously, and its significance as well as the specific mechanism involved has not been identified.

Many mechanisms are known to diminish the response of NMDARs, including surface membrane receptor internalization, $\mathrm{Ca}^{2+}$-dependent inactivation, glycine-dependent desensitization, and glycine-independent desensitization $^{[11-13]}$. Therefore, we designed a series of experiments to investigate the problem. Because some previous studies have raised the possibility that NMDARs undergo regulated transport to and from the cell surface ${ }^{[14,15]}$, we measured the expression of surface NMDARs while applying a 
high concentration of NMDA with or without glycine. Our results ruled out the possibility of membrane protein internalization.

On the other hand, $\mathrm{Ca}^{2+}$-dependent inactivation is a reversible decrease in peak current, which can be induced by a rise in extracellular $\mathrm{Ca}^{2+}$ concentration, without agonist activation of the receptor itself ${ }^{[16,17]}$. Desensitization is a decrease in the current response induced by the persistent presence of a glutamate site agonist ${ }^{[8]}$. Thus, it is intriguing to consider that the inhibitory phenomenon we revealed in the present study, which is in contrast to the glycinedependent desensitization, may be a glycine-dependent inactivation of NMDARs.

Glycine-dependent desensitization is a well-known phenomenon. While binding to the glycine site of NMDARs, glycine potentiates glutamate-elicited responses and inhibits the desensitization of NMDARs ${ }^{[4,8,9]}$. We also found glycinedependent desensitization. When NMDA was applied at 30 $\mu \mathrm{mol} / \mathrm{L}$, glycine elevated the peak current and $\mathrm{Ca}^{2+}$ influx and decreased the desensitization of $I_{\mathrm{NMDA}}$. These results are consistent with previous reports ${ }^{[4,8,9]}$. Glycine, a coagonist for activation of NMDARs, is also an inhibitory neurotransmitter in the central nervous system.

Next, we sought to exclude the possibility of the involvement of glycine receptor activation by using strychnine, an antagonist of this receptor. We found that strychnine did not have any notable influence on the inhibitory effect of glycine on the increase of $\left[\mathrm{Ca}^{2+}\right]_{\mathrm{i}}$ evoked by 1 $\mathrm{mmol} / \mathrm{L} \mathrm{NMDA}$. To identify the potential target of this glycinedependent inactivation of NMDARs, the cultured hippocampal neurons were treated with 7-CK, an antagonist of the glycine site of NMDARs. Result showed that 7-CK blocked the inhibition by glycine of the $\mathrm{Ca}^{2+}$ influx evoked by $1 \mathrm{mmol} / \mathrm{L}$ NMDA. We suggest that this inactivating effect of glycine is mediated by binding to the glycine site of NMDARs.

Consequently, our results strongly suggest that the inhibitory effect we found is a novel effect of glycine, which is determined by the concentration of NMDA and glycine binding. Moreover, the inhibitory effect appears to be mediated via binding to the NMDAR glycine site, and not by the activation of glycine receptors or the internalization of NMDARs primed by glycine binding.

Modulation of the NMDAR response is an important mechanism for the physiological and pathophysiological consequences of NMDAR activation ${ }^{[1-3]}$. The concentrations of glutamate, glycine, and $\mathrm{Ca}^{2+}$ at the synaptic level are important determinants of the ion current flowing through the NMDAR-gated ion channel. The combination of different forms of inactivation and desensitization determines the overall degree of current response following the activation of NMDARs. Therefore, the regulation of NMDAR function, plus the effects of many other modulating factors, including polyamines, zinc, $\mathrm{pH}$, redox agents and intracellular signaling molecules ${ }^{[3,12]}$, is rather complicated. The results of the present study suggest that this complexity is further increased by a novel glycine-dependent inactivation process.

In addition, we showed that continuing exposure to NMDA induced LDH release and decreased viability in cultured hippocampal neurons, and glycine facilitated this damaging effect of $30 \mu \mathrm{mol} / \mathrm{L}$ NMDA. However, increasing the concentration of glycine did not increase the damaging effect of $300 \mu \mathrm{mol} / \mathrm{L}$ NMDA, but decreased LDH leakage dose-dependently, indicating that a cytoprotective effect of glycine occurs when neurons are exposed to higher concentrations of NMDA. This result is in line with a previous in vivo experiment, in which glycine over $1 \mathrm{mmol} / \mathrm{L}$ did not significantly increase the 100 and $200 \mu \mathrm{mol} / \mathrm{L}$ NMDAevoked depolarization in the rat striatum ${ }^{[18]}$. However, the investigators in that study did not exclude the possibility of the involvement of strychnine-sensitive glycine receptors, as glycine at the concentrations used is known to activate these receptors. Therefore, the novel inhibitory influence of glycine on NMDARs reported here has potential physiological and pathophysiological significance for protecting neurons from excessive activation of NMDARs when glutamate is released above physiological levels due to excessive glutamatergic activity.

In conclusion, our results suggest that a novel glycinedependent inactivation occurs while NMDARs are activated by $300 \mu \mathrm{mol} / \mathrm{L}$ NMDA. This inhibitory effect occurs via 
binding to the glycine site of NMDARs but is not due to activation of the strychnine-sensitive glycine-receptorgated chloride channel. The inhibitory influence of glycine on NMDARs adds a new insight to our knowledge about the complexity of, and feedback loops involved in, synaptic transmission.

Acknowledgements: This work was supported by Project Funded by the Priority Academic Program Development of Jiangsu Higher Education Institutions.

\section{References:}

[1] Petrovic M, Horak M, Sedlacek M, Vyklicky L Jr. Physiology and pathology of NMDA receptors. Prague Med Rep 2005, 106: 113136.

[2] Rao VR, Finkbeiner S. NMDA and AMPA receptors: old channels, new tricks. Trends Neurosci 2007, 30: 284-291.

[3] Gardoni F, Di Luca M. New targets for pharmacological intervention in the glutamatergic synapse. Eur J Pharmacol 2006, 545: 2-10.

[4] Johnson JW, Ascher P. Glycine potentiates the NMDA response in cultured mouse brain neurons. Nature 1987, 325: 529-531.

[5] Kleckner NW, Dingledine R. Requirement for glycine in activation of NMDA-receptors expressed in Xenopus oocytes. Science 1988, 241: 835-837.

[6] Laube B, Hirai H, Sturgess M, Betz H, Kuhse J. Molecular determinants of agonist discrimination by NMDA receptor subunits: analysis of the glutamate binding site on the NR2B subunit. Neuron 1997, 18: 493-503.

[7] Anson LC, Chen PE, Wyllie DJ, Colquhoun D, Schoepfer R. Identification of amino acid residues of the NR2A subunit that control glutamate potency in recombinant NR1/NR2A NMDA receptors. J
Neurosci 1998, 18: 581-589.

[8] Mayer ML, Vyklicky L Jr, Clements J. Regulation of NMDA receptor desensitization in mouse hippocampal neurons by glycine. Nature 1989, 338: 425-427.

[9] Benveniste M, Clements J, Vyklicky L Jr, Mayer ML. A kinetic analysis of the modulation of N-methyl-D-aspartic acid receptors by glycine in mouse cultured hippocampal neurones. J Physiol 1990, 428: 333-357.

[10] Brewer GJ, Torricelli JR, Evege EK, Price PJ. Optimized survival of hippocampal neurons in B27-supplemented Neurobasal, a new serum-free medium combination. J Neurosci Res 1993, 35: 567576.

[11] Dingledine R, Borges K, Bowie D, Traynelis SF. The glutamate receptor ion channels. Pharmacol Rev 1999, 51: 7-61.

[12] Liu Y, Zhang J. Recent development in NMDA receptors. Chin Med J (Engl) 2000, 113: 948-956.

[13] Nong Y, Huang YQ, Ju W, Kalia LV, Ahmadian G, Wang YT, et al. Glycine binding primes NMDA receptor internalization. Nature 2003, 422: 302-307.

[14] Roche KW, Standley S, McCallum J, Dune Ly C, Ehlers MD, Wenthold RJ. Molecular determinants of NMDA receptor internalization. Nat Neurosci 2001, 4: 794-802.

[15] Snyder EM, Philpot BD, Huber KM, Dong X, Fallon JR, Bear MF. Internalization of ionotropic glutamate receptors in response to mGluR activation. Nat Neurosci 2001, 4: 1079-1085.

[16] Vyklicky L Jr. Calcium-mediated modulation of N-methyl- $D$ aspartate (NMDA) responses in cultured rat hippocampal neurones. J Physiol 1993, 470: 575-600.

[17] Rosenmund C, Feltz A, Westbrook GL. Calcium-dependent inactivation of synaptic NMDA receptors in hippocampal neurons. J Neurophysiol 1995, 73: 427-430.

[18] Obrenovitch TP, Hardy AM, Urenjak J. High extracellular glycine does not potentiate N-methyl- $D$-aspartate-evoked depolarization in vivo. Brain Res 1997, 746: 190-194. 